\title{
Novel dietary strategy for overcoming the antinutritional effects of soyabean whey of high agglutinin content
}

\author{
BY A. PUSZTAI ${ }^{1}$, G. GRANT ${ }^{1}$, S. BARDOCZ ${ }^{1}$, E. GELENCSER ${ }^{2}$ AND GY. HAJOS ${ }^{2}$ \\ ${ }^{1}$ Rowett Research Institute, Bucksburn, Aberdeen AB2I 9SB \\ ${ }^{2}$ Central Food Research Institute, 1022-Budapest, Hungary
}

(Received 26 April 1996 - Revised 21 October 1996 - Accepted 1 November 1996)

\begin{abstract}
A diet-switching experiment, which aimed to improve the utilization of soyabean whey was carried out for $61 \mathrm{~d}$ with young rats. Feeding was arranged in such a way that after a few days on the soyabean diet, the rats were switched to a high-quality lactalbumin diet for a short period, after which the cycle was repeated several times. The weights of the rats at the end of the soyabean phases were significantly less than those of animals pair-fed on a high-quality diet throughout. However, the test group regained the weight loss after switching to the lactalbumin diet. After three cycles there were no significant differences between the weights of the test rats fed on a poor soyabean diet for over a third of the experiment and those fed on the lactalbumin diet throughout. Feed conversion was always significantly higher with test rats in the lactalbumin period than with continually pairfed controls. Similarly, faecal $N$ losses were significantly higher for test rats in the soyabean phase, but these differences disappeared after switching to the lactalbumin diet. At the end of the experiment there were no significant differences in body protein or lipids between the groups although the pancreas was significantly heavier while the liver was lighter in soyabean-fed rats. The high destruction of trypsin inhibitors in the gut suggests that they probably had little effect on protein digestion in the gut. In contrast, as selective depletion of the agglutinin from soyabean whey removed the nutritional benefit in the lactalbumin part of the cycle, the improved feed conversion in this period must have been the result mainly of the survival and functionality of soyabean agglutinin and the benefits due to the hyperplastic growth and faster renewal of the gut surface it induced. As processing is unnecessary, this novel method is cheap and can be easily adapted for the use of soyabean whey, regarded as a waste product.
\end{abstract}

Diet-switching: Feed conversion efficiency: Soyabean whey: Agglutinin

The use of soyabean in human food is increasing and soyabean proteins often supply the bulk of dietary protein in animal nutrition. Unfortunately, as soyabeans contain a number of antinutrients, mainly a lectin (or agglutinin) and two trypsin inhibitors, the efficiency of nutritional utilization of diets containing soyabean products is below that expected from chemical composition (Gupta, 1987). This is particularly so when these are fed for long periods (Rackis et al. 1986) and in the case of soyabean whey, which contains most of the antinutrients (Grant et al. 1986). It is a commonly-held view that soyabean products could be more extensively used in both human and animal diets if their antinutritional effects were reduced.

The antinutritive activity of lectins stems from their ability to recognize and specifically bind to carbohydrate side-chains of membrane glycans of brush-border epithelial cells. As some of these are receptors of growth and/or metabolic factors, 
avidly-binding lectins induce hyperplastic growth and faster cell turnover of the smallintestinal epithelium (Pusztai et al. 1990) and the nutritional cost of this at low dietary lectin levels is a moderate reduction of the growth of the animal (Bardocz et al. 1996). Dietary lectins are also powerful stimulants of the growth of the pancreas (Bardocz et al. 1995); both acinar tissues and the islets are affected and this can also contribute to the reduction in nutritional value of diets containing lectins. Finally by modulating the body's hormone balance, lectin effects on general metabolism, possibly reinforced by immune responses, may also have overall antinutritive consequences (Bardocz et al. 1996). However, toxicity symptoms only occur when lectins are included in diets at high enough levels to cause substantial overgrowth of bacteria such as $E$. coli, resulting in serious intestinal damage and malabsorption of nutrients (Banwell et al. 1988; Pusztai $e$ t al. 1993; Bardocz et al. 1996). In fact, the interactions between true lectins, gut receptors and bacteria are the main determinants of whether lectins are toxic or beneficial (Pusztai \& Bardocz, 1995).

Unlike lectins, trypsin inhibitors do not interact with the brush border of the small intestine but are thought to exert their antinutritional effects by reducing the efficiency of digestion of dietary proteins in the gut (Gallaher \& Schneeman, 1986). However, trypsin inhibitors are powerful inducers of the growth of the pancreas (Liener, 1994). In fact the continuous overstimulation of the pancreas may be one of the most harmful consequences of the long-term consumption of diets containing trypsin inhibitors (Pusztai et al. 1992).

The antinutrient content of most soyabean products is generally removed by processing based on various methods of heat treatment (Liener, 1994). However, most of these are expensive and can lead to losses of essential amino acids and production of toxic byproducts. Although cheaper and more efficient heat-processing may eventually be developed, other options for reducing the antinutritional effects of soyabean products include diet manipulation and the design of new feeding strategies. Rendering soyabean products, and particularly the little-used whey fraction, free of the main negative effects of antinutrients could bring considerable economic benefits to the feed industry and animal producers.

A novel approach is described in the present paper which is based on the hypothesis that even though there is probably a nutritional cost of the faster renewal of the absorptive surface of the small bowel in the gut growth-stimulating phase, the improved efficiency of absorption and utilization of nutrients of high-quality diets after the lectin is removed may compensate for it. As, under these conditions, less of the nutrient intake is used for protein synthesis and turnover in a small intestine which is gradually returning to pre-stimulation size due to the reversibility of the lectin action, additional nutritional benefits may also be derived. To test this idea rats were fed first on a soyabean albumin diet of moderate lectin content for a short time, used as a model material for soyabean whey, followed by feeding on a high-quality diet also for short times. The poor growth of rats fed on soyabean albumin excluded the possibility of setting up a negative control group of rats which were to be fed continuously for $61 \mathrm{~d}$ on this diet (Grant $e$ t al. 1986; Gupta, 1987). By comparing the growth, digestibility and feed conversion efficiency of test rats with those of control rats pair-fed on a high-quality lactalbumin (LA) diet throughout, it was shown that the negative effects of soyabean albumin were compensated for by the increased feed conversion efficiency in the LA diet part of the cycle. It was also clearly shown that this beneficial effect was due to the presence of soyabean agglutinin (SBA) in the diet, because with its removal from soyabean albumin, feed conversion was not improved in the LA diet part of the cycle. 


\section{MATERIALS AND METHODS}

\section{Purification of antinutrients}

Soyabean (Glycine max) albumin (SBALB), which like soyabean whey concentrates most of the soyabean antinutrients, SBA, a SBA-depleted soyabean albumin (LD-SBALB), Kunitz trypsin (EC 3.4.21.4) inhibitor (KTI) and Bowman-Birk trypsin/chymotrypsin (EC 3.4.21.1) inhibitor (BBI) were purified from soyabeans (Real Foods, Edinburgh, Lothian) as described previously (Pusztai et al. 1991).

\section{Antibody production}

Antibodies to KTI, BBI and LA were developed in rabbits according to the method of Harboe \& Inglid (1973) as described previously (Hajos et al. 1995). Antibody to SBA was obtained from Sigma Chemical Co. (Poole, Dorset).

\section{Competitive indirect ELISA}

Indirect ELISA assays were used for the quantitative determination of SBA, KTI and BBI in the SBALB preparation and for quantifying the survival of SBA, KTI or BBI and $\alpha-\mathrm{LA}$, the control protein, in gut samples (Hajos et al. 1995). However, with LA the ELISA plates were coated with LA and the immune-complex was formed by using a rabbit anti-LA immunoglobulin G-type antibody. Results were expressed as percentage material recovered of the dose intubated intragastrically.

\section{Electrophoretic separation of antinutrients in gut samples}

SDS gel electrophoresis, followed by semi-dry transblotting on to nitrocellulose membranes and immunostaining with antigen-specific antibodies to the antinutrients were carried out as before (Hajos et al. 1995).

\section{Animal management}

All management and experimental procedures in the present study were carried out in strict accordance with the requirements of UK Animals (Scientific Procedures) Act 1986 by staff licensed under this Act to carry out such procedures.

Male Hooded-Lister rats (Rowett strain) were weaned at $19 \mathrm{~d}$ and given free access to stock diet (Labsure, Manea, Cambs.) for $7 \mathrm{~d}$ after which they were fed ad libitum on LA control diet $(100 \mathrm{~g} \mathrm{LA}$ protein/ $\mathrm{kg}$; Table 1) for $3 \mathrm{~d}$, followed by feeding $6 \mathrm{~g}$ of the same diet/rat per $\mathrm{d}$ for $5 \mathrm{~d}$. Water was freely available at all times. The rats were then divided into two groups, with five rats in each group. The diet for the experimental group contained $100 \mathrm{~g}$ protein $/ \mathrm{kg}$ based on SBALB (Table 1). The control group of rats was fed on the LA diet throughout the experiment and its amount was restricted to the voluntary intake of the test rats. The experimental design was such (see Fig. 1) that initially the soyabean group was fed on the soyabean diet for $7 \mathrm{~d}$, switched to the LA diet for $8 \mathrm{~d}$, followed by the soyabean diet for $7 \mathrm{~d}$ and a $7 \mathrm{~d}$ LA diet period respectively. Next, after another $6 \mathrm{~d}$ on the soyabean diet followed by $20 \mathrm{~d}$ on the LA diet, the rats were finally exposed to the soyabean diet for a $5 \mathrm{~d}$ period. On the following morning which was the 61 st day of the combined feeding experiment, all rats were given $2 \mathrm{~g}$ LA diet after which the soyabean group was intragastrically intubated with $280 \mathrm{mg}$ SBALB dissolved in $2 \mathrm{ml}$ saline while the controls received saline only. Rats were killed by halothane overdose exactly 90 min later, to ensure that all intubated materials were still in the small intestine, and fully 
Table 1. Composition of powdered diets ( $\mathrm{g} / \mathrm{kg}$ diet)

\begin{tabular}{lcc}
\hline $\begin{array}{l}\text { Diet ... } \\
\text { Ingredients }\end{array}$ & Control & $\begin{array}{c}\text { Soyabean albumins } \\
\text { (SBALB) }\end{array}$ \\
\hline Lactalbumin & 120 & 0 \\
Soyabean albumins & 0 & 110 \\
Maize starch & 380 & 380 \\
Potato starch & 100 & 100 \\
Glucose & 150 & 150 \\
Maize oil & 150 & 150 \\
Vitamins* & 50 & 50 \\
Minerals* & 50 & 50 \\
L-Tryptophan & 0 & 0.3 \\
L-Methionine & 0 & 1.2 \\
L-Phenylalanine & 0 & 1.0 \\
L-Leucine & 0 & 2.3 \\
L-Isoleucine & 0 & 2.6 \\
L-Valine & 0 & 2.6 \\
Silicic acid & 0.4 & 0.4 \\
\hline \hline
\end{tabular}

* For composition of vitamin and mineral mixes see Grant et al. (1993).

dissected. Stomach and small intestine were removed and the latter was cut into sections $100 \mathrm{~mm}$ long. The lumen of each tissue was washed with $2 \mathrm{ml}$ ice-cold distilled water, freeze-dried and later reconstituted with distilled water $(1 \mathrm{mg} D M / 100 \mu \mathrm{l})$ and used for ELISA. All tissues were freeze-dried and weighed. Rat bodies were also freeze-dried and used for the determination of protein and lipid contents. Stomach and small-intestinal sections were homogenized (three times) with $0.1 \mathrm{M}$-D-galactose solutions $(5 \mathrm{ml} / \mathrm{dry}$ sample) and these extracts were used for ELISA. Throughout the experiment faeces were collected daily and used for $\mathrm{N}$ determinations.

In a control experiment the first cycle of the switching was carried out but with three groups of rats (five rats per group). The first group was fed on the SBALB-diet for $7 \mathrm{~d}$, followed by the LA diet for $8 \mathrm{~d}$, as before. The second group was also given a soyabean preparation in the first $7 \mathrm{~d}$ but with LD-SBALB replacing SBALB in the diet and was then switched to the LA diet. A third group (controls) was pair-fed on the LA diet for the whole $15 \mathrm{~d}$ of the experiment. Weight gain and feed conversion efficiency of the two test groups were compared with those of the control group in the two separate parts of the cycle.

\section{Statistical analyses}

The results were subjected to one-way ANOVA using the 'Minitab' computer program (Penn State University, State College, PA, USA). The significance of difference between treatment groups was estimated using Student's $t$ test.

\section{RESULTS}

\section{Composition of soyabean albumin and lectin-depleted soyabean albumin}

The preparation used in the feeding experiment was shown by ELISA to contain $38.7 \mathrm{~g}$ $\mathrm{SBA}, 180 \mathrm{~g} \mathrm{KTI}$ and $73.9 \mathrm{~g} \mathrm{BBI} / \mathrm{kg}$ SBALB. LD-SBALB contained less than $4 \mathrm{~g} \mathrm{SBA} / \mathrm{kg}$. 


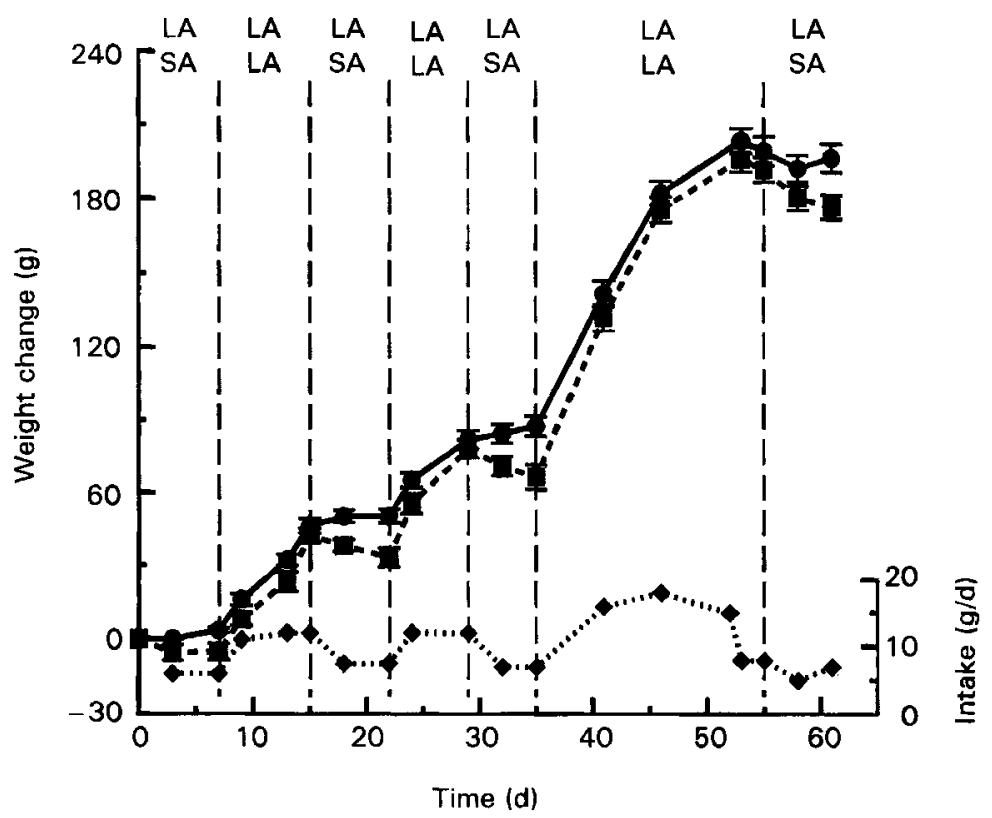

Fig. 1. Growth of rats fed on a soyabean albumin (SA) diet followed by a lactalbumin (LA) diet in repeated cycles ( $\square$ ) in comparison with that of rats pair-fed on control LA diet throughout the experiment (O). Values are means and standard deviations for five rats per dietary group. Times of switching the rats to different diets and food intakes are also indicated in the diagram. $(\cdots)$, Feed intake.

Table 2. Body weight $(B W)$ and composition of rats fed on a control diet or fed for alternate periods on a test diet containing soyabean albumin (SBALB) and the control diet $\dagger$

(Values are means and standard deviations for five rats per group)

\begin{tabular}{|c|c|c|c|c|}
\hline \multirow[t]{2}{*}{ Diet ... } & \multicolumn{2}{|c|}{ Control } & \multicolumn{2}{|c|}{ Test (SBALB) } \\
\hline & Mean & SD & Mean & SD \\
\hline Initial BW (g) & 88.8 & 3.5 & 86.5 & $2 \cdot 1$ \\
\hline Final BW (g) & 283.5 & 7.5 & $263.6 *$ & $7 \cdot 2$ \\
\hline Dry BW (g) & $111 \cdot 5$ & $3 \cdot 0$ & $104 \cdot 6^{*}$ & $3 \cdot 2$ \\
\hline Lipid (g) & $54 \cdot 1$ & 4.5 & 51.8 & $5 \cdot \overline{5}$ \\
\hline Protein $(\mathrm{g})$ & 45.7 & 1.5 & 44.2 & $2 \cdot 1$ \\
\hline Lipid (g/kg dry BW) & $485 \cdot 2$ & $33 \cdot 3$ & 493.8 & $36 \cdot 0$ \\
\hline Protein (g/kg dry BW) & 410.7 & 19.9 & $402 \cdot 1$ & $25 \cdot 5$ \\
\hline
\end{tabular}

* Mean values were significantly different from those of the control group, $P<0.05$.

$\dagger$ For details of diets and procedures, see Table 1 and pp. 935-936.

\section{Nutritional effects}

The weight of rats fed alternately on soyabean and LA diets was always significantly less at the end of each soyabean-feeding period, including the last one, than that of the corresponding pair-fed control rats (Tables 2 and 3). However, rats in the test group always grew faster in the LA diet period following soyabean feeding than control rats kept on the LA diet throughout (Fig. 1; Table 3). Moreover, feed conversion efficiency of the test group in the LA period was always significantly higher than that of the control group 
A. PUSZTAI ET AL.

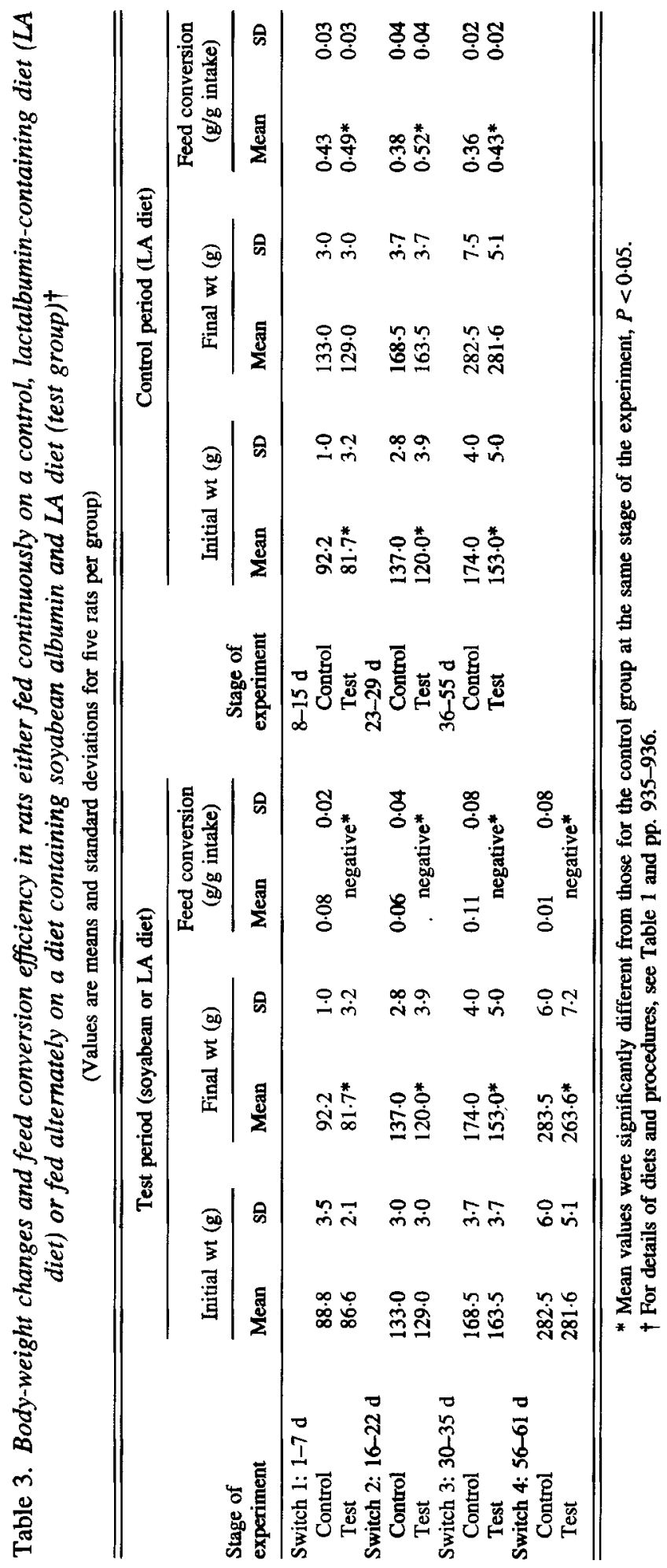




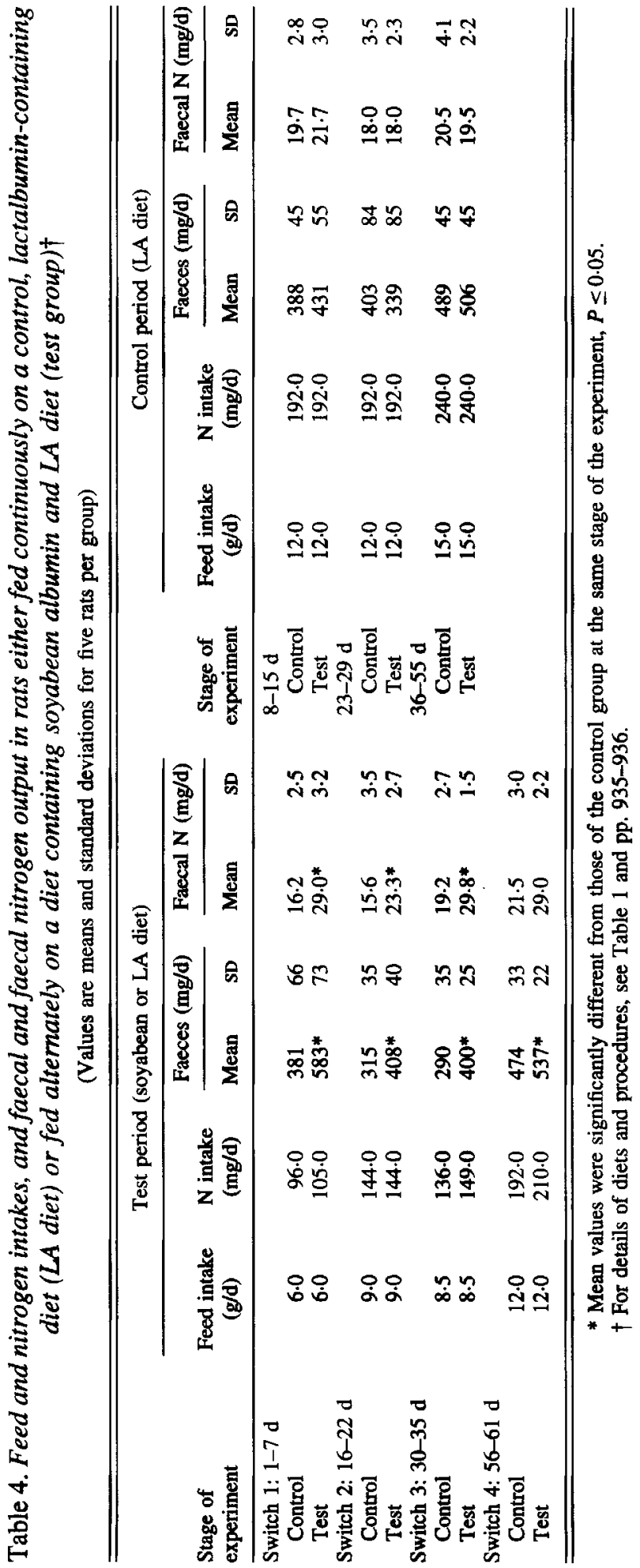


Table 5. Weight gain and feed conversion efficiency in rats either fed continuously on a control, lactalbumin-containing diet ( $L A$ diet), or fed on diets containing untreated soyabean albumin

(SBALB) or lectin-depleted soyabean albumin (LD-SBALB) followed by the LA diet*

(Values are means and standard deviations for five rats per dietary group)

\begin{tabular}{|c|c|c|c|c|c|c|c|c|c|c|c|c|}
\hline \multirow[b]{3}{*}{ Diet } & \multicolumn{6}{|c|}{ Test period (soyabean or LA diet) } & \multicolumn{6}{|c|}{ Control period (LA diet) } \\
\hline & \multicolumn{2}{|c|}{ Initial wt (g) } & \multicolumn{2}{|c|}{ Final wt (g) } & \multicolumn{2}{|c|}{$\begin{array}{c}\text { Feed conversion } \\
(\mathrm{g} / \mathrm{g} \text { intake })\end{array}$} & \multicolumn{2}{|c|}{ Initial wt (g) } & \multicolumn{2}{|c|}{ Final wt (g) } & \multicolumn{2}{|c|}{$\begin{array}{l}\text { Feed conversion } \\
\text { (g/g intake) }\end{array}$} \\
\hline & Mean & SD & Mean & SD & Mean & SD & Mean & SD & Mean & SD & Mean & SD \\
\hline Control (LA) & $83.4^{\mathrm{a}}$ & 1.7 & $88 \cdot 0^{a}$ & $1 \cdot 1$ & $0 \cdot 13^{2}$ & 0.03 & $88 \cdot 0^{2}$ & $1 \cdot 1$ & $131 \cdot 5^{\mathrm{a}}$ & 1.0 & $0.45^{a}$ & 0.03 \\
\hline LD-SBALB & $83.4^{\mathrm{a}}$ & 1.5 & $84 \cdot 2^{b}$ & 1.3 & $0.02^{b}$ & 0.02 & $84 \cdot 2^{b}$ & 1.0 & $125 \cdot 5^{\mathrm{b}}$ & 1.5 & $0.43^{\mathrm{a}}$ & 0.03 \\
\hline SBALB & $83.4^{\mathrm{a}}$ & 1.0 & $80 \cdot 0^{\mathrm{c}}$ & $1 \cdot 3$ & \multicolumn{2}{|c|}{ negative $e^{c}$} & $80 \cdot 0^{c}$ & $1 \cdot 3$ & $129.9^{\mathrm{a}}$ & 1.5 & $0.52^{b}$ & 0.02 \\
\hline
\end{tabular}

a,b.c Mean values within a column with unlike superscript letters were significantly different, $P \leqslant 0.05$.

* For details of diets and procedures, see Table 1 and pp. 935-936.

(Table 3). In the soyabean-feeding period the weight and $\mathrm{N}$ content of faeces of the test group were significantly higher than those of the control rats (Table 4). Despite this, possibly apart from the first exposure to SBALB, apparent digestibilities in rats fed on the LA diet and the soyabean diet, particularly after correction for antinutrient survival, were not significantly different. In the LA periods there were no significant differences in the faecal values between the test and control groups. Moreover, neither lipid and protein contents nor their concentration in the rat bodies were significantly different in the two groups even though rats in the test group were killed in the soyabean phase of the experiment (Table 2).

Rats fed on LD-SBALB in the test period gained more weight and had a better feed conversion efficiency than those fed on SBALB but their performance was still below that of rats fed on the LA diet (Table 5). Moreover, although the growth (Fig. 2) and feed conversion efficiency (Table 5) of the rats fed on the LD-SBALB diet were improved in the LA part of the cycle, their performance was still only comparable with that of control rats kept on the LA diet throughout. In contrast, this was significantly better with rats which were switched from SBALB to LA than those fed on the LA diet all the time (Fig. 2; Table 5).

\section{Effects on internal organs}

The weights of stomach, intestines, spleen, kidneys, thymus, lungs, heart and gastrocnemius muscles were not affected by alternate feeding of rats with soyabean and LA diets for $61 \mathrm{~d}$. However, the absolute weight of the pancreas was significantly higher and that of the liver lower in the test group than in the controls (Table 6).

\section{Recovery of soyabean antinutrients from the gut}

At 90 min after the intragastric intubation of rats of the test group with $280 \mathrm{mg}$ SBALB on the last (61st) day of the experiment, only 0.72 (SD 0.05 ) \% of the original dose of SBA $(10.84 \mathrm{mg})$ was recovered in stomach washings whereas nearly $50 \%$ was recovered from the small-intestinal sections. Only a small proportion of this, 4.8 (SD 2.3) \% of the original dose, was found in free form in the lumen, mainly in the last $200 \mathrm{~mm}$ of the small intestine 
Table 6. Tissue dry weights ( $\mathrm{mg}$ ) of rats after $61 \mathrm{~d}$ of receiving either a lactalbumin-containing diet continuously (control) or a soyabean albumin-containing diet followed by the lactalbumincontaining diet in repeated cycles $\dagger$

(Values are means and standard deviations for five rats per dietary group)

\begin{tabular}{|c|c|c|c|c|}
\hline \multirow{2}{*}{$\begin{array}{l}\text { Diet... } \\
\text { Tissue }\end{array}$} & \multicolumn{2}{|c|}{ Control } & \multicolumn{2}{|c|}{ Test } \\
\hline & Mean & SD & Mean & SD \\
\hline Stomach & 317 & 19 & 286 & 15 \\
\hline Small intestine & 1491 & 80 & 1520 & 49 \\
\hline Caecum & 195 & 37 & 185 & 39 \\
\hline Colon & 256 & 79 & 299 & 38 \\
\hline Pancreas & 334 & 33 & $439 *$ & 60 \\
\hline Spleen & 119 & 7 & 109 & 10 \\
\hline Liver & 2304 & 48 & $2101^{*}$ & 97 \\
\hline Kidneys & 396 & 27 & 373 & 19 \\
\hline Thymus & 83 & 13 & 92 & 8 \\
\hline Lungs & 336 & 45 & 313 & 68 \\
\hline Heart & 188 & 10 & 190 & 15 \\
\hline Gastrocnemius & 578 & 51 & 589 & 75 \\
\hline
\end{tabular}

* Mean values were significantly different from those for the control group, $P<0.05$.

† For details of diets and procedures, see Table 1 and pp. 935-936.

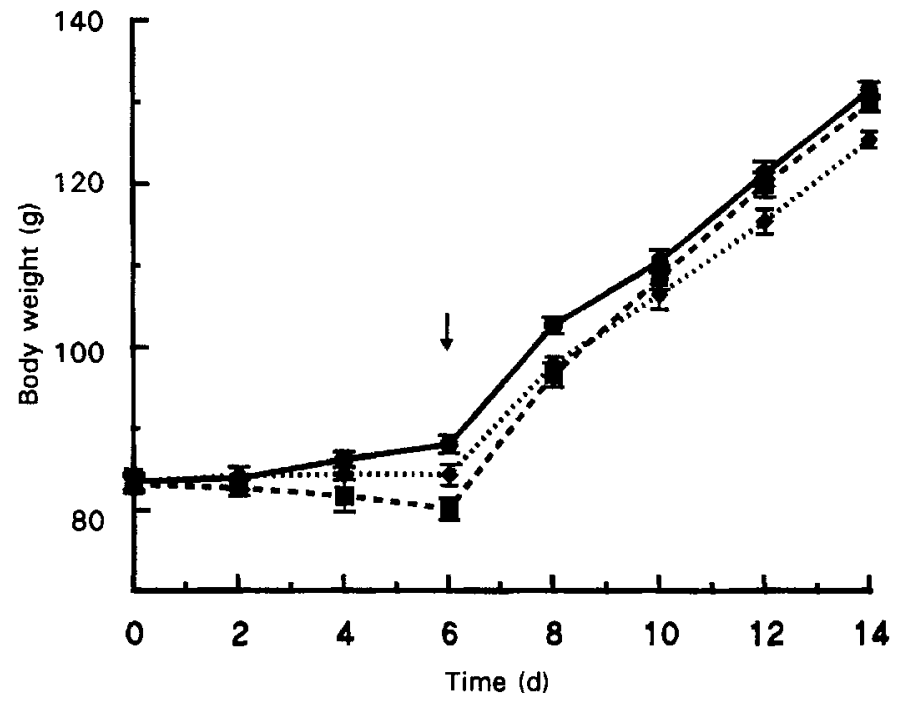

Fig. 2. Growth of rats fed on diets containing soyabean albumin of high lectin content $(\square)$ or low lectin content $(\bullet)$ for $6 \mathrm{~d}$ followed by a lactalbumin diet for $8 \mathrm{~d}$ in comparison with that of rats pair-fed on the lactalbumin (control) diet throughout the experiment ( $)$. Values are means for five rats, with standard deviations represented by vertical bars. $t$, Time of switching the diets.

and most, 44.1 (SD 2.4) \%, was specifically bound to the brush border and could only be eluted by washing the sections with $0.1 \mathrm{M}$-galactose solution. The bound SBA was distributed fairly evenly in the middle intestinal sections, with smaller amounts at the two extremes. 


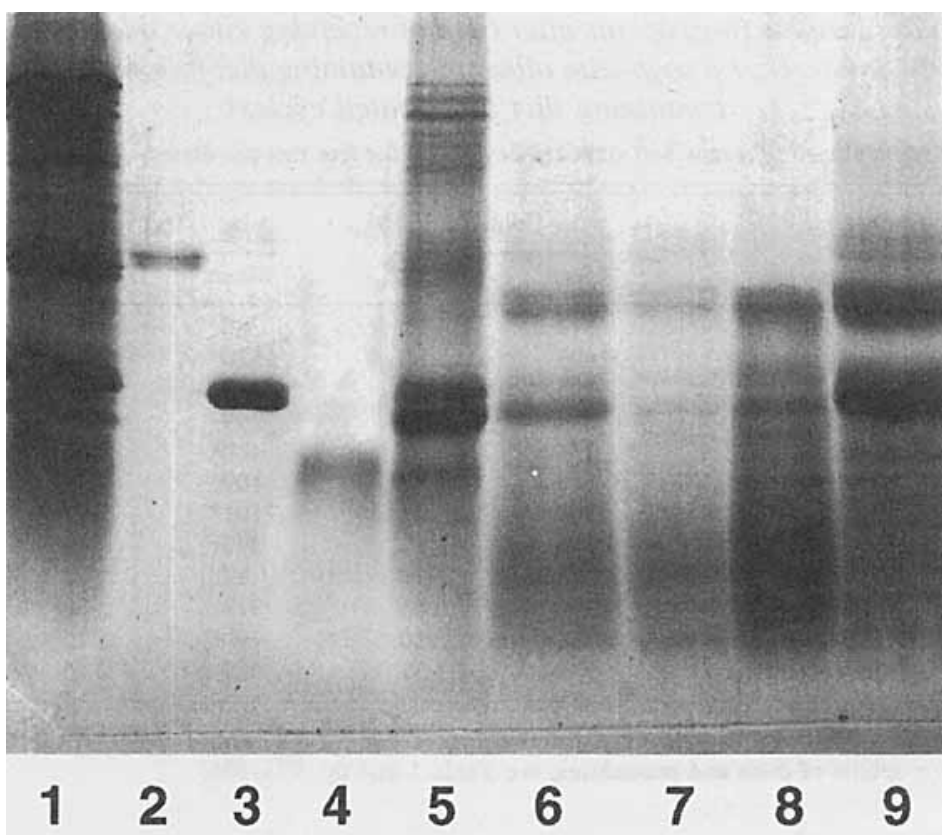

Fig. 3. SDS gel electrophoresis patterns of soyabean albumin, purified soyabean antinutrients and washings from the gut of rats at the completion of the experiment. The following samples were run: lane 1, soyabean albumin fraction; lane 2, soyabean agglutinin; lane 3, Kunitz trypsin inhibitor; lane 4, Bowman-Birk protease inhibitor; lane 5, stomach washing; and lanes 6-9, washings of consecutive small-intestinal sections.

About 20.2 (SD 7.1) \% of the original dose of KTI $(50.4 \mathrm{mg}$ ) was recovered from washings of the stomach but only 7.2 (SD 0.4 ) \% of the dose was present in the smallintestinal washings, mainly from sections of the last $200 \mathrm{~mm}$ of the small intestine.

Of the original dose of BBI (20.69 mg) 5.2 (SD 4-4) \% was recovered from the stomach with 11.3 (SD 8.7) \% of the dose being present in intestinal washings, mainly from the middle sections of the small bowel.

No measurable amounts of $\alpha$-LA were detected in the stomach or small intestine of control rats $90 \mathrm{~min}$ after being given $2 \mathrm{~g}$ LA diet in the morning of the last day.

SDS gel electrophoretic analysis (Fig. 3) and transblotting followed by reaction with the appropriate specific antibodies (results not shown) qualitatively confirmed the presence of SBA, KTI and BBI in gut washings of rats of the test group.

\section{DISCUSSION}

This study has confirmed and extended the large body of experimental evidence that protein antinutrients have a major impact in determining the nutritional value of raw soyabean based foods and feedstuffs (for recent review see Liener, 1994) particularly when soyabean-based diets are fed exclusively and for long periods. The main antinutrients responsible for reducing the nutritional value of raw soyabean and, to a certain extent, some processed soyabean products, are believed to be the soyabean lectin and the two trypsin inhibitors. 
Clearly, antinutrients can only be expected to exert negative effects on the nutritional value of the diet if they survive the transit through the gastrointestinal tract and also retain their physiological activity. However, only a relatively small proportion of BBI and KTI remained detectable in the small intestine $90 \mathrm{~min}$ after administration, thus partially confirming their low recovery in acute experiments with fasted rats (Hajos et al. 1995). Our low recovery of KTI in fed rats may appear to be at odds with the relatively high survival of KTI in acute studies with fasted rats, but the difference probably reflects the protection of KTI in the fasted rats because of the reduced stomach acidity under these conditions. Thus, as both BBI and KTI are largely degraded under normal conditions of feeding and the small part that escapes degradation is neutralized by complexing by luminal proteases, the inhibitors are unlikely to have major effects on protein digestibility in vivo. In fact, that is exactly what was found in the present study (Table 4). However, as undenatured trypsin inhibitors stimulate the growth and metabolism of the pancreas which is generally regarded as undesirable, particularly for humans and in the long term (Pusztai et al. 1992), their removal from the diet may still be necessary.

In contrast to trypsin inhibitors, at least $50 \%$ of the SBA administered was recovered, showing that this lectin is protected during its passage through the small intestine regardless of whether it is given acutely (Hajos et al. 1995) or fed continuously as in the present experiment. Moreover, SBA retained its biological activity as most of it was bound to the gut wall and could only be removed by washing with galactose, the haptenic sugar (Pusztai et al. 1990; Hajos et al. 1995). As the hyperplastic growth of the small intestine resulting from exposure to SBA requires more nutrients, an increased proportion of the intake is diverted to the gut instead of being used for body growth. Consequently, rat growth was retarded and feed conversion efficiency became negative at all stages when soyabean was fed (Table 4), confirming that SBA is likely to be one of the main factors responsible for some of the antinutritive effects of soyabean and that this is indeed a true lectin effect since, with the possible exception of the last switch, it was not diminished on repeated exposures to the soyabean diet during the experiment and unaffected by the gut or the humoral immune systems.

As the involvement of SBA in the antinutritive effects of soyabean is generally accepted, one of the aims of soyabean processing is to inactivate its biological activity by various heat-treatments (Calderon de la Barca et al. 1991; Liener, 1994). In contrast, the present paper describes an alternative novel method for overcoming the adverse effects of soyabean whey which is based on the exploitation of the biological activity of SBA on the gut. Thus, this method is dependent on the presence of SBA in the diet rather than on its removal. However, to minimize the negative nutritional effects of soyabean whey in the diet which would have led to unacceptable growth depression in the long term (Grant et al. 1986), in the present study rats were fed in cycles in which soyabean and LA diets were fed alternately. The benefits and effectiveness of this approach can be gauged from the results in Tables 3 and 4 which show that the weight gain of the test group of rats after $55 \mathrm{~d}$ was not significantly different from that of the pair-fed LA group despite the fact that the test animals were fed on a poor-quality diet for $20 \mathrm{~d}$ out of the total $55 \mathrm{~d}$ while the LA group received a high-quality diet for the entire period.

The rationale of this approach is that rats are fed for a few days on a diet containing low levels of a lectin which stimulates the growth of the small intestine (anti-nutritive phase; Pusztai et al. 1990) and then switched to a high-quality diet for a few days (benefit phase), after which the cycles are repeated. The hyperplastic growth and increased turnover of the small intestine (Pusztai et al. 1990) in the lectin part of the cycle increase the proportion of the diet that is used for this gut growth and this leads to a moderate growth 
depression of the animal (antinutritive-phase). However, as there is a quick recovery after the lectin part of the cycle, it is possible that the enhanced rate of renewal of the surface of the small intestine due to the faster epithelial turnover might increase its absorptive potential after the removal of the lectin (Pusztai et al. 1979). Additionally, as the rate of gut protein synthesis is substantially reduced after cessation of the growth stimulation by SBA, a higher proportion of the nutrients can be used for supporting body growth. Thus, the more efficient use of the protein and other nutrients of the diet in the high-quality dietary period of the feeding cycle (benefit phase; Tables 3 and 4) compensates for the reduction in nutritional performance during the SBALB period. It was also clearly demonstrated by feeding rats a SBALB preparation from which about $90 \%$ of SBA had been removed (LDSBALB) that the benefit can only be obtained when SBA is present in the antinutritive phase (Table 5) and that it is not caused by a simple compensatory effect of switching from a poor to a high-quality diet.

Although many methods other than heat-treatment have been suggested for the removal of antinutrients from soyabean, such as germination, fermentation (tofu, etc), chemical treatments and the use of genetic variants of low antinutrient content, relatively few of these have found widespread use with industry or consumers. Our novel method involves no processing and it can also be potentially applicable to soyabean whey which is largely a waste product and not utilized for animal feeding. Although the principle of this method is clearly demonstrated by our results, it is regarded only as a first step and further developments may increase its usefulness and general acceptance. Thus, as can be seen from Fig. 1, and as is also indicated by other preliminary data, restricting the soyabean period to not more than $3 \mathrm{~d}$ would probably be advantageous because $48-72 \mathrm{~h}$ is enough to complete a full cycle of intestinal turnover and thereby obtain the benefits of higher nutrient utilization rates in the control feeding part of the cycle. Moreover, the LA feeding part of the cycle is also probably best restricted to about $5 \mathrm{~d}$ to obtain maximum improvements in feed conversion efficiency.

In conclusion: this diet-switching experiment in which rats were fed alternately in short cycles on diets containing soyabean or LA has shown that it is possible to take advantage of the hyperplastic growth induced by SBA to improve the utilization of highquality nutrients in the period following exposure to SBA. The main attraction of this novel method is that it may enable us to use soyabean waste products of relatively high lectin content, including the whey fraction remaining after the removal of globulins, for animal feeding and, possibly other dietary uses, without expensive processing.

This work was supported by the Scottish Office Agriculture, Environment and Fisheries Department. Drs Gelencser and Hajos are grateful to OMFB (Office for Technical and Technological Development) and FM (Ministry of Agriculture) Hungary and for a travel grant to Dr Hajos by a European COST 98 Action.

\section{REFERENCES}

Banwell, J. G., Howard, R., Cooper, D. \& Costerton, J. W. (1988). Bacterial overgrowth by indigenous microflora in the phytohemagglutinin fed rat. Canadian Journal of Microbiology 34, 1009-1013.

Bardocz, S., Grant, G., Ewen, S. W. B., Duguid, T. J., Brown, D. S., Englyst, K. \& Pusztai, A. (1995). Reversible effect of phytohaemagglutinin on the growth and metabolism of rat gastrointestinal tract. Gut 37, 353-360.

Bardocz, S., Grant, G., Pusztai, A., Franklin, M. F. \& Carvalho, A. de F. F. U. (1996). The effect of phytohaemagglutinin at different dietary concentrations on the growth, body composition and plasma insulin of the rat. British Journal of Nutrition 76, 613-626.

Calderon de la Barca, A. M., Vazquez-Moreno, L. \& Robles-Burgueno, M. R. (1991). Active soybean lectin in foods: isolation and quantitation. Food Chemistry 39, 321-327. 
Gallaher, D. \& Schneeman, B. O. (1986). Nutritional and metabolic response to plant inhibitors of digestive enzymes. In Nutritional and Toxicological Significance of Enzyme Inhibitors in Foods, pp. 167-184 [M. Friedman, editor]. New York: Plenum Press.

Grant, G., Dorward, P. M. \& Pusztai, A. (1993). Pancreatic enlargement is evident in rats fed diets containing raw soybeans (Glycine max) or cowpeas (Vigna unguiculata) for 800 days but not in those fed diets based on kidney beans (Phaseolus vulgaris) or lupinseed (Lupinus angustifolius). Journal of Nutrition 123, 2207-2215.

Grant, G., McKenzie, N. H., Watt, W. B., Stewart, J. C., Dorward, P. M. \& Pusztai, A. (1986). Nutritional evaluation of soya beans (Glycine max): nitrogen balance and fractionation studies. Journal of the Science of Food and Agriculture 37, 1001-1010.

Gupta, Y. P. (1987). Nutritive value of soybean. International Joumal of Tropical Agriculture 5, $247-279$.

Hajos, Gy., Gelencser, E., Pusztai, A., Grant, G., Sakhri, M. \& Bardocz, S. (1995). Biological effects and survival of trypsin inhibitors and the agglutinin from soybean in the small intestine of the rat. Journal of Agricultural and Food Chemistry 43, 165-170.

Harboe, N. \& Inglid, A. (1973). Immunization, isolation of immunoglobulins, estimation of antibody titre. Scandinavian Journal of Immunology 2 (Suppl. 1), 161-164.

Liener, I. E. (1994). Implications of antinutritional components in soybean foods. Critical Reviews in Food Science and Nutrition 34, 31-67.

Pusztai, A. \& Bardocz, S. (1995). Physiological roles of lectins in plants and the effects of their inclusion in the diet on the gut and metabolism of mammals. In Phytochemicals and Health. Proceedings of the 10th Annual Penn State Symposium in Plant Physiology, pp. 179-191 [D.L. Gustine and H. E. Flores, editors]. Rockville, MD: American Society of Plant Physiologists.

Pusztai, A., Clarke, E. M. W. \& King, T. P. (1979). The nutritional toxicity of Phaseolus vulgaris lectins. Proceedings of the Nutrition Society 38, 115-120.

Pusztai, A., Ewen, S. W. B., Grant, G., Peumans, W. J., van Damme, E. J. M., Rubio, L. \& Bardocz, S. (1990). The relationship between survival and binding of plant lectins during small intestinal passage and their effectiveness as growth factors. Digestion 46 (Suppl. 2), 308-316.

Pusztai, A., Grant, G., Brown, D. J., Stewart, J. C. \& Bardocz, S. (1992). Nutritional evaluation of the trypsin (EC 3.4.21.4) inhibitor from cowpea (Vigna unguiculata Walp.). British Joumal of Nutrition 68, 783-791.

Pusztai, A., Grant, G., Duguid, T., Brown, D. S., Peumans, W. J., Van Damme, E. J. M. \& Bardocz, S. (1993). Kidney bean lectin-induced Escherichia coli overgrowth in the small intestine is blocked by GNA, a mannosespecific lectin. Journal of Applied Bacteriology 75, 360-368.

Pusztai, A., Watt, W. B. \& Stewart, J. C. (1991). A comprehensive scheme for the isolation of trypsin inhibitors and the agglutinin from soybean seeds. Journal of Agricultural and Food Chemistry 39, 862-866.

Rackis, J. J., Wolf, W. J. \& Baker, E. C. (1986). Protease inhibitors in plant foods; content and inactivation. In Nutritional and Toxicological Significance of Enzyme Inhibitors in Foods, pp. 299-331 [M. Friedman, editor]. New York: Plenum Press. 